\title{
Curvas de Dose-Resposta para Avaliação do Controle de Fluxos de Emergência de Plantas Daninhas Pelo Herbicida IMAZAPIC ${ }^{1}$
}

\author{
Dose-Response Curves to Evaluate the Control of Weed Emergence Fluxes by Imazapic \\ CARVALHO, S.J.P. ${ }^{2}$, LOMBARDI, B.P. ${ }^{3}$, NICOLAI, M. ${ }^{2}$, LÓPEZ-OVEJERO, R.F. ${ }^{2}$, \\ CHRISTOFFOLETI, P.J. ${ }^{4}$ e MEDEIROS, D. ${ }^{5}$
}

\begin{abstract}
RESUMO - O objetivo deste trabalho foi avaliar o controle de dois fluxos de emergência das plantas daninhas capim-marmelada (Brachiaria plantaginea) e capim-colchão (Digitaria horizontalis) pelo herbicida imazapic, aplicado em condição de pré-emergência, por meio de curvas de dose-resposta. O delineamento experimental foi o de blocos ao acaso, com quatro repetições; cada parcela constou de um vaso de $3 \mathrm{~L}$ de capacidade, preenchido com solo argiloso, acrescido de sementes de capim-marmelada e capim-colchão. Sendo D a dose recomendada do imazapic $\left(140 \mathrm{~g} \mathrm{ha}^{-1}\right)$, os tratamentos foram: 4D, 2D, D, 1/2D, 1/4D, 1/8D, $1 / 16 \mathrm{D}$ e ausência do herbicida. Foram realizadas avaliações visuais de controle aos 30 e 60 dias após a infestação (DAI) e de massa seca aos 60 DAI. Após a colheita da biomassa resultante do primeiro fluxo de emergência presente nas parcelas, os vasos foram novamente semeados com as plantas daninhas e foram realizadas novas avaliações de controle aos 30 e 60 dias após reinfestação (DAR) e de massa seca aos 60 DAR. A partir dos resultados obtidos, pode-se afirmar que: o imazapic inibiu o desenvolvimento de ambas as plantas daninhas, alcançando resultados superiores a $80 \%$ de controle em todas as avaliações, para a dose recomendada, nos dois fluxos de emergência; a eficácia no controle de capim-colchão foi ligeiramente superior à do controle do capim-marmelada; e o herbicida imazapic apresentouse como uma opção interessante para manejo dessas plantas daninhas.
\end{abstract}

Palavras-chave: Digitaria horizontalis, Brachiaria plantaginea, controle residual.

ABSTRACT - The objective of this work was to evaluate the control of two emergence fluxes of the weeds Brachiaria plantaginea and Digitaria horizontalis by the herbicide imazapic applied under pre-emergence conditions, by analyzing the dose-response curves. The experimental design adopted was randomized blocks, with four replicates, with each plot being a $3 L$ capacity pot, filled with clay soil plus Brachiaria plantaginea and Digitaria horizontalis seeds. Considering $D$ as the recommended rate of imazapic $\left(140 \mathrm{~g} \mathrm{ha}^{-1}\right)$, the treatments were: $4 D, 2 D, D, 1 / 2 D, 1 / 4 D, 1 / 8 D, 1 / 16 D$ and no herbicide. Visual evaluations of control at 30 and 60 Days After Infestation (DAI) and dry weight at 60 DAI were performed. After harvest of the biomass present in the plots, resulting from the first flux, the pots were seeded again followed by control evaluations at 30 and 60 Days After Re-infestation (DAR) and dry weight at 60 DAR. The results showed that imazapic inhibited the development of both weeds, reaching results higher than $80 \%$ of control in all the evaluations for the recommended dose, in both emergence fluxes; the efficacy in the control of Digitaria horizontalis was slightly superior than the control of Brachiaria plantaginea; imazapic was presented as an interesting option for management of these weeds.

Key words: Digitaria horizontalis, Brachiaria plantaginea, residual control.

Recebido para publicação em 8.3.2005 e na forma revisada em 5.9.2005.

Eng.-Agr., alunos do Programa de Pós-Graduação em Fitotecnia da Escola Superior de Agricultura "Luiz de Queiroz" - ESALQ/ USP, Caixa Postal 09, 13419-900 Piracicaba-SP, <sjpcarvalho@yahoo.com.br>, <marcelon@esalq.usp.br>, <rfloveje@esalq.usp.br>; ${ }^{3}$ Aluna de Graduação em Engenharia Agronômica da ESALQ/USP, <bplombar@esalq.usp.br>; ${ }^{4}$ Professor Associado do Departamento de Produção Vegetal - ESALQ/USP, < pjchrist@esalq.usp.br>. ${ }^{5}$ Eng.-Agr., M.S., Téc. Desenvolvimento de Mercado -BASF S.A., <daniel.medeiros@basf-sa.com.br>. 


\section{INTRODUÇÃO}

As plantas daninhas são um dos principais fatores bióticos presentes no agroecossistema da cana-de-açúcar que têm a capacidade de interferir no desenvolvimento e na produtividade da cultura (Kuva et al., 2003). Estima-se que existam cerca de 1.000 espécies de plantas daninhas que habitam este agroecossistema, distribuídas nas distintas regiões produtoras do mundo (Arévalo, 1979); dentre elas, podemse destacar o capim-marmelada (Brachiaria plantaginea) e o capim-colchão (Digitaria horizontalis). A interferência negativa resultante da presença das plantas daninhas nas áreas agrícolas produtoras de cana-de-açúcar pode causar reduções na quantidade e na qualidade do produto colhido e diminuir o número de cortes viáveis, além de aumentar os custos em cerca de 30\% para cana-soca e de 15 a 20\% para cana-planta (Lorenzi, 1988; 1995).

A interferência é influenciada por fatores ligados à própria cultura (espécie ou variedade, espaçamento e densidade de plantio), à época e extensão do período de convivência e aos fatores característicos das plantas daninhas (composição específica, densidade e distribuição) (Pitelli, 1985). No caso da cana-deaçúcar, as características próprias da cultura favorecem o prolongamento do período de convivência e conseqüente competição, quando comparada com as culturas de cereais, como milho ou soja. Trabalhos para a situação de cana-planta indicam que o período crítico de prevenção da interferência (PCPI) situa-se, em média, entre 30 e 100 dias após a deposição dos toletes (Rolim \& Christoffoleti, 1982; Kuva et al., 2003). Poucos estudos foram realizados para a cultura em condição de soqueira, porém acredita-se que o PCPI se localiza entre 20 e 100 dias após a emergência da cultura (Procópio et al., 2004).

Com relação às plantas daninhas, sabese que as diferenças específicas e intrínsecas dos propágulos promovem a desuniformidade temporal do processo germinativo. Essa desuniformidade é decorrente, principalmente, da coexistência de inúmeros e complexos mecanismos de dormência em cada propágulo e da distribuição diferencial dos propágulos no perfil do solo (Pitelli \& Pitelli, 2004). O recrutamento das plântulas é conseqüência do sucesso na germinação das sementes e do subseqüente estabelecimento dos indivíduos, o que é determinado pelo número de sementes no perfil do solo e por condições ambientais diretamente adjacentes às sementes (Boyd \& Acker, 2003). As sementes dispersas nos solos agrícolas têm sua germinação e dormência regidas por fatores intrínsecos das espécies e, também, por características do meio, como: disponibilidade de água, luz, temperatura e profundidade de semeadura. Caso as condições não sejam as ideais, as sementes podem permanecer viáveis nos solos por longos períodos (Carmona, 1992; Kogan, 1992).

Atualmente, o principal método de controle das plantas daninhas é o químico, por meio da aplicação de herbicidas, tanto na condição de pré como de pós-emergência destas plantas (Hernandez et al., 2001). Segundo Freitas et al. (2004), o controle químico de plantas daninhas em áreas de cana-de-açúcar é uma prática bastante difundida em todo o país. Acredita-se que em áreas com necessidade de controle dessas plantas por longos períodos, como é o caso da cana-de-açúcar, haja necessidade de utilização de herbicidas com ação residual prolongada. Entre as diversas opções de herbicidas registrados para a cultura da cana-de-açúcar encontra-se o imazapic, herbicida pertencente ao grupo químico das imidazolinonas, que apresenta ação em pré e pós-emergência inicial, sendo recomendado no controle de gramíneas, folhas largas e perenes de difícil controle. Além disso, pode apresentar periodo de controle efetivo nos solos superior a 120 dias (Procópio et al., 2004).

Assim, o objetivo deste trabalho foi avaliar o controle de dois fluxos de emergência das plantas daninhas capim-marmelada (Brachiaria plantaginea) e capim-colchão (Digitaria horizontalis) pelo herbicida imazapic aplicado em condição de pré-emergência, por meio de curvas de dose-resposta.

\section{MATERIAL E MÉTODOS}

O experimento foi conduzido em casa de vegetação do Departamento de Produção Vegetal da ESALQ/USP, no período compreendido entre agosto e dezembro de 2004. O delineamento experimental adotado foi do tipo blocos ao acaso, com quatro repetições. Os 
tratamentos são conseqüência de um esquema fatorial $8 \times 2$, sendo oito os niveis do fator herbicida (doses de imazapic) e dois os niveis do fator planta daninha (capim-colchão e capim-marmelada), totalizando 64 parcelas. Cada parcela constou de um vaso de $3 \mathrm{~L}$ de capacidade, preenchido com solo argiloso (46,5\% de argila, $14,5 \%$ de silte e $39 \%$ de areia) e $0,5 \mathrm{~g}$ de sementes de capim-marmelada ou $0,3 \mathrm{~g}$ de sementes de capim-colchão, almejando uma densidade estimada de 100 plantas $\mathrm{m}^{-2}$. Para todos os vasos, administrou-se adubação proporcional de $37,5 \mathrm{~kg} \mathrm{ha}^{-1}$ de $\mathrm{N}$ e $\mathrm{P}$ e $50 \mathrm{~kg} \mathrm{ha}^{-1}$ de $\mathrm{K}$. As propriedades químicas do solo utilizado no experimento estão apresentadas na Tabela 1 .

Sendo D a dose recomendada do imazapic (140 $\left.\mathrm{g} \mathrm{ha}^{-1}\right)$, os niveis do fator herbicida (doses) foram: 4D, 2D, D, 1/2D, 1/4D, 1/8D, 1/16D e ausência do herbicida. Todas as aplicações foram realizadas em câmara de aplicação, utilizando um bico de pulverização tipo leque, com jato plano, modelo XR 80.02, calibrado para um volume de calda correspondente a $200 \mathrm{~L} \mathrm{ha}^{-1}$. Logo após a aplicação, todos os vasos receberam uma lâmina d'água proporcional a uma precipitação de $10 \mathrm{~mm}$, sendo então transportados até a casa de vegetação e irrigados sempre que necessário.

A condução do experimento foi dividida em duas etapas. Na primeira, avaliou-se a eficácia do imazapic sobre o primeiro fluxo de emergência das duas espécies de plantas daninhas quando o herbicida foi aplicado logo após semeadura, ou seja, 0 dia após infestação (DAI). Foram feitas avaliações visuais de controle percentual aos 30 e 60 DAI e de massa seca aos 60 DAI.

A segunda etapa iniciou-se após a mensuração da biomassa da primeira etapa, ou seja, aos 60 DAI. Após a realização da pesagem da parte aérea das plantas, os vasos foram novamente semeados com as mesmas quantidades de sementes utilizadas na primeira etapa, as quais foram cobertas com uma fina camada de solo peneirado. Contudo, nesse instante, os vasos não foram submetidos a nova aplicação do produto, uma vez que o objetivo desta fase foi avaliar a eficácia do imazapic no controle do segundo fluxo de emergência das espécies de plantas daninhas. Na segunda etapa foram realizadas avaliações visuais de controle percentual aos 30 e 60 dias após reinfestação (DAR) - respectivamente 90 e 120 DAI - e de massa seca aos 60 DAR.

Em ambas as etapas, as avaliações de controle foram baseadas na escala da Asociation...-ALAM (1974), com controles extremos de 0 (ausência de controle) e 100\% (controle absoluto). Os dados de biomassa foram corrigidos para valores percentuais, partindo-se do princípio de que as parcelas que permaneceram sem aplicação de herbicida possuem 100\% de biomassa e as demais possuem percentuais desta biomassa, em conseqüência da redução imposta pelo produto.

Os dados foram analisados através da aplicação do teste F sobre a análise da variância, com o objetivo de detectar a significância da interação fatorial. Quando significativos, os niveis do fator herbicida (doses) foram analisados com o emprego de regressões nãolineares do tipo log-logístico, segundo o modelo proposto por Seefeldt et al. (1995):

$$
y=a+\frac{b}{\left[1+\left(\frac{x}{c}\right)^{d}\right]}
$$

em que $y=$ porcentagem de controle ou de biomassa; $x=$ dose do herbicida em g i.a. ha-1 e $a, b, c$ e $d=$ coeficientes da curva, de modo que $a$ é o limite inferior da curva, $b$ é a diferença entre o ponto máximo e o mínimo da curva, $c$ é a dose que proporciona $50 \%$ de resposta da variável dependente e $d$ é a declividade da curva ao redor de $c$.

Tabela 1 - Propriedades químicas do solo utilizado no experimento

\begin{tabular}{|c|c|c|c|c|c|c|c|c|c|c|c|}
\hline $\mathrm{pH}$ & M.O. & P resina & $\mathrm{K}$ & $\mathrm{Ca}$ & $\mathrm{Mg}$ & $\mathrm{H}+\mathrm{Al}$ & $\mathrm{Al}$ & S.B. & CTC & $\mathrm{V}$ & $\mathrm{m}$ \\
\hline$\left(\mathrm{CaCl}_{2}\right)$ & $\left(\mathrm{g} \mathrm{dm}^{-3}\right)$ & $\left(\mathrm{mg} \mathrm{dm}^{-3}\right)$ & \multicolumn{7}{|c|}{$\left(\mathrm{mmol}_{\mathrm{c}} \mathrm{dm}^{-3}\right)$} & \multicolumn{2}{|c|}{$\%$} \\
\hline 6,0 & 8 & 1 & 0,3 & 36 & 11 & 15 & 0 & 47 & 62 & 76 & 0 \\
\hline
\end{tabular}


O modelo log-logístico apresenta vantagens, uma vez que um dos termos integrantes da equação (c) é uma estimativa do valor de $\mathrm{GR}_{50}$ (Christoffoleti, 2002). O GR (growth $_{50}$ reduction $50 \%$ e é a dose do herbicida em gramas do ingrediente ativo por hectare que proporciona o valor de $50 \%$ de controle ou de redução de crescimento da planta daninha (Christoffoleti \& López-Ovejero, 2004). Como complementação do trabalho, realizou-se o cálculo matemático da dose do herbicida, em g i.a. ha ${ }^{-1}$, que proporcionaria $80 \%$ de controle ou de redução no crescimento das plantas daninhas, $\mathrm{GR}_{80}$, para cada uma das variáveis, visto que $80 \%$ é o controle mínimo exigido pela legislação em vigor.

Embora um dos parâmetros obtidos (c) já forneça a estimativa do valor de $x$ que proporciona $50 \%$ de resposta ou de redução da massa em $y$, a realização do cálculo matemático permite a correção de eventuais distorções do modelo, oferecendo valores mais próximos dos reais. Para realização do cálculo optou-se pela inversão do modelo log-logístico, deixando-o em função de $y$.

$$
x=c * \sqrt[d]{\frac{b}{(y-a)}-1}
$$

Observando o modelo log-logístico inverso, nota-se que $c$ será igual a $x$ toda vez que o resultado da raiz apresentar valor igual a 1 . Por meio dos devidos cálculos matemáticos, ressalta-se que, para que esta condição seja atendida, é necessário que o y lançado na raiz seja a média aritmética entre o valor máximo e o valor mínimo obtidos para a variável dependente. Quando se estudam curvas do tipo dose-resposta, usualmente o primeiro ponto é a dose zero, que tem por resultado zero de controle. Assim, a raiz, no caso de uma curva de dose-resposta, será igual a 1 toda vez que o y lançado for a metade do ponto máximo obtido. Conclui-se que $c$ só promoverá fiel estimativa de GR50 quando, em uma curva de doseresposta, o ponto mínimo de controle for igual a 0 e o ponto máximo da variável reposta se estabilizar em 100\%, uma vez que, neste caso, a condição de raiz igual a 1 será atendida, pois o y lançado será 50 .

Sabendo que nem sempre o valor de 100\% de controle é alcançado em curvas de dose-resposta, o valor do parâmetro $c$ foi desconsiderado e realizou-se o cálculo matemático de $\mathrm{GR}_{50}$. No instante em que se substitui o $y$ da equação inversa por 50 (controle de 50\% da população) ou pela metade do valor de massa seca obtido na dose OD, alcança-se o valor exato de $\mathrm{GR}_{50}$ em termos de g i.a. ha ${ }^{-1}$. Da mesma forma, quando se substitui $y$ por 80 , obtém-se a dose que proporciona $\mathrm{GR}_{80}$.

\section{RESULTADOS E DISCUSSÃO}

O teste $\mathrm{F}$ sobre a análise da variância demonstrou a significância do fator herbicida, do fator espécie e também da interação fatorial entre herbicida e espécie para todas as variáveis analisadas no trabalho. Com a aplicação de regressões não-lineares sobre os dados obtidos no experimento, foram definidos os parâmetros $a, b, c$ e $d$ da equação log-logística (Seefeldt et al., 1995), que estão apresentados na Tabela 2. A partir desses parâmetros puderam ser calculados os valores de $\mathrm{GR}_{50} \mathrm{e}$ $\mathrm{GR}_{80}$ para as duas espécies de plantas daninhas, em todas as variáveis analisadas (Tabela 3).

A planta daninha capim-marmelada foi eficientemente controlada pelo herbicida imazapic em todas as avaliações, cujos valores encontrados para a dose recomendada mantiveram-se sempre superiores a $80 \%$. Os valores percentuais de controle alcançados para cada dose estão representados na Figura 1. Nas avaliações de 30 e 60 DAI, o controle de $80 \%$ $\left(\mathrm{GR}_{80}\right)$ foi alcançado com 79,2 e 63,1 g i.a. ha ${ }^{-1}$, respectivamente. $\mathrm{Na}$ segunda etapa, o controle de $80 \%$ foi alcançado com 96,9 e $115,6 \mathrm{~g}$ i.a. ha ${ }^{-1}$, respectivamente para as avaliações de 30 e 60 DAR. Na comparação dos valores encontrados na primeira e segunda etapas do experimento, observa-se que foram necessários incrementos de 17,7 e $52,5 \mathrm{~g}$ i.a. ha ${ }^{-1}$ para manutenção do controle de $80 \%$ nas avaliações relacionadas a 30 e 60 dias, respectivamente (Tabela 3).

O capim-colchão foi ainda mais sensivel ao herbicida imazapic que o capim-marmelada, e a dose recomendada do produto também apresentou controles sempre superiores a $80 \%$. Os valores percentuais de controle obtidos para as demais doses estão representados 
na Figura 2. Durante a primeira etapa do experimento, esta espécie exigiu a aplicação de 23,5 e 28,6 g i.a. ha ${ }^{-1}$ de imazapic para que fosse alcançado o controle de $80 \%$, nas avaliações de 30 e 60 DAI, respectivamente. Estes valores são cerca de três vezes menores que aqueles exigidos pelo capim-marmelada. $\mathrm{Na}$ segunda etapa, os valores de $\mathrm{GR}_{80}$ alcançados nas avaliações de 30 e 60 DAR foram, respectivamente, de 44,1 e 75,9 g i.a. ha-1. Também no caso do capim-colchão observou-se a necessidade do incremento de 20,6 e 47,3 g i.a. ha-1 entre a primeira e a segunda etapa do experimento para manutenção do controle de $80 \%$, nas avaliações relacionadas a 30 e 60 dias, respectivamente (Tabela 3 ).

Tabela 2 - Estimativas dos parâmetros $a, b, c$ e $d$ e do coeficiente de determinação $\left(\mathrm{r}^{2}\right)$ do modelo log-logístico, para as plantas daninhas Brachiaria plantaginea e Digitaria horizontalis, em todas as variáveis avaliadas durante os dois fluxos de emergência

\begin{tabular}{|c|c|c|c|c|c|c|c|c|c|c|}
\hline \multicolumn{11}{|c|}{ Avaliação do primeiro fluxo de plantas daninhas } \\
\hline \multirow{2}{*}{ Variável } & \multicolumn{5}{|c|}{ Brachiaria plantaginea } & \multicolumn{5}{|c|}{ Digitaria horizontalis } \\
\hline & $\mathrm{a}$ & $\mathrm{b}$ & $\mathrm{c}$ & $\mathrm{d}$ & $\mathrm{r}^{2}$ & $\mathrm{a}$ & $\mathrm{b}$ & $\mathrm{c}$ & $\bar{d}$ & $\mathrm{r}^{2}$ \\
\hline Controle (\%) $30 \mathrm{DAI}$ & 0,593 & 100,492 & 37,333 & $-1,762$ & 0,997 & 0,187 & 100,055 & 11,195 & $-1,846$ & 0,998 \\
\hline Controle (\%) 60 DAI & $-1,473$ & 98,454 & 37,791 & $-3,059$ & 0,999 & $-0,723$ & 99,395 & 17,974 & $-3,153$ & 0,999 \\
\hline Massa Seca (\%) & 0,093 & 100,838 & 26,889 & 3,286 & 1,000 & $-0,444$ & 100,405 & 8,437 & 2,141 & 1,000 \\
\hline \multicolumn{11}{|c|}{ Avaliação do segundo fluxo de plantas daninhas } \\
\hline \multirow{2}{*}{ Variável } & \multicolumn{5}{|c|}{ Brachiaria plantaginea } & \multicolumn{5}{|c|}{ Digitaria horizontalis } \\
\hline & a & $\mathrm{b}$ & $\mathrm{c}$ & $\mathrm{d}$ & $\mathrm{r}^{2}$ & a & $\mathrm{b}$ & $\mathrm{c}$ & $\mathrm{d}$ & $\mathrm{r}^{2}$ \\
\hline Controle (\%) 30 DAR & 2,175 & 94,799 & 65,234 & $-3,853$ & 0,998 & 1,000 & 98,150 & 32,898 & $-4,851$ & 0,999 \\
\hline Controle (\%) 60 DAR & 3,677 & 99,343 & 75,384 & $-2,802$ & 0,990 & 0,331 & 100,033 & 45,731 & $-2,694$ & 1,000 \\
\hline Massa Seca $(\%)$ & 3,957 & 88,865 & 69,582 & 13,430 & 0,979 & 0,656 & 95,315 & 37,896 & 7,658 & 0,995 \\
\hline
\end{tabular}

Tabela 3 - Valores de $\mathrm{GR}_{50}$ e $\mathrm{GR}_{80}\left(\mathrm{~g}\right.$ i.a. $\mathrm{ha}^{-1}$ ) e controle ou biomassa percentual (corrigido - C e observado - O) na dose recomendada de imazapic $\left(140 \mathrm{~g} \mathrm{ha}^{-1}\right)$, para os dois fluxos das plantas daninhas, em todas as variáveis avaliadas. Piracicaba, 2004

\begin{tabular}{|c|c|c|c|c|c|c|c|c|}
\hline \multicolumn{9}{|c|}{ Primeiro Fluxo das Plantas Daninhas } \\
\hline \multirow{3}{*}{ Variável } & \multicolumn{4}{|c|}{ Brachiaria plantaginea } & \multicolumn{4}{|c|}{ Digitaria horizontalis } \\
\hline & \multicolumn{2}{|c|}{$\begin{array}{c}\text { GR } \\
\left(\text { g i.a. } h^{-1}\right)^{-1}\end{array}$} & \multicolumn{2}{|c|}{$\begin{array}{c}\text { Dose }-140 \mathrm{~g} \mathrm{ha}^{-1} \\
(\%)\end{array}$} & \multicolumn{2}{|c|}{$\begin{array}{c}\text { GR } \\
\left(\text { g i.a. } \text { ha }^{-1}\right)\end{array}$} & \multicolumn{2}{|c|}{$\begin{array}{c}\text { Dose }-140 \mathrm{~g} \mathrm{ha}^{-1} \\
(\%)\end{array}$} \\
\hline & 50 & 80 & $\mathrm{C}$ & $\mathrm{O}$ & 50 & 80 & $\mathrm{C}$ & $\mathrm{O}$ \\
\hline Controle (\%) aos 30 DAI & 36,6 & 79,2 & 92,2 & 96,5 & 11,1 & 23,5 & 99,3 & 99,3 \\
\hline Controle $(\%)$ aos $60 \mathrm{DAI}$ & 38,9 & 63,1 & 98,2 & 99,3 & 18,2 & 28,6 & 98,5 & 99,3 \\
\hline Massa Seca $(\%)$ aos 60 DAI & 27,1 & 41,2 & 0,5 & 0,3 & 8,4 & 15,9 & 0,0 & 0,1 \\
\hline \multicolumn{9}{|c|}{ Segundo Fluxo das Plantas Daninhas } \\
\hline \multirow{3}{*}{ Variável } & \multicolumn{4}{|c|}{ Brachiaria plantaginea } & \multicolumn{4}{|c|}{ Digitaria horizontalis } \\
\hline & \multicolumn{2}{|c|}{$\begin{array}{c}\text { GR } \\
\left(\text { g i.a. ha }{ }^{-1}\right) \\
\end{array}$} & \multicolumn{2}{|c|}{$\begin{array}{c}\text { Dose }-140 \mathrm{~g} \mathrm{ha}^{-1} \\
(\%)\end{array}$} & \multicolumn{2}{|c|}{$\begin{array}{c}\text { GR } \\
\left(\text { g i.a. } \text { ha }^{-1}\right)\end{array}$} & \multicolumn{2}{|c|}{$\begin{array}{c}\text { Dose }-140 \mathrm{~g} \mathrm{ha}^{-1} \\
(\%)\end{array}$} \\
\hline & 50 & 80 & $\mathrm{C}$ & $\mathrm{O}$ & 50 & 80 & $\mathrm{C}$ & $\mathrm{O}$ \\
\hline Controle (\%) aos 30 DAR & 65,5 & 96,9 & 92,2 & 89,8 & 32,9 & 44,0 & 99,1 & 98,3 \\
\hline Controle $(\%)$ aos 60 DAR & 71,8 & 115,6 & 88,1 & 94,0 & 45,5 & 75,9 & 95,7 & 96,8 \\
\hline Massa Seca (\%) aos 60 DAR & 69,2 & 77,9 & 3,96 & 11,6 & 37,5 & 45,3 & 0,7 & 0,60 \\
\hline
\end{tabular}




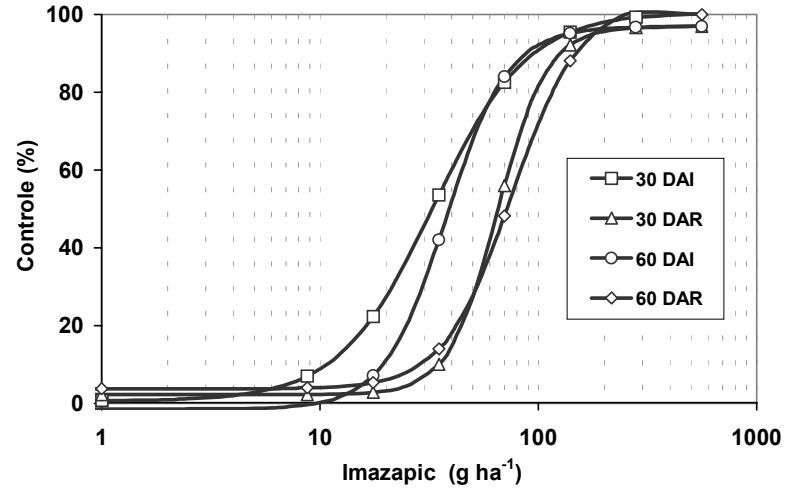

Figura 1 - Controle (\%) de Brachiaria plantaginea pelo herbicida imazapic, avaliado aos 30 DAI, 30 DAR, 60 DAI e 60 DAR. Piracicaba, 2004.

Sabe-se que a adsorção das imidazolinonas pelos colóides dos solos é baixa ou muito baixa, sendo altamente influenciada pelos teores de argila e de matéria orgânica, e os solos com maiores destes teores requerem maiores doses dos produtos (Miller \& Westra, 1998a, b). Embora o solo utilizado no experimento apresentasse elevado teor de argila $(46,5 \%)$, o teor de matéria orgânica foi baixo $\left(8 \mathrm{~g} \mathrm{dm}^{-3}\right)$, fato que pode ter contribuído para a manutenção dos elevados índices de controle apresentados pelo produto mesmo nas avaliações de 60 DAR (120 dias contínuos após a aplicação).

No entanto, tem-se diagnosticado que a principal forma de decomposição das imidazolinonas nos solos é a microbiana (Mangels, 1991), e a luz solar (raios ultravioleta) participa com a menor parte das perdas dos compostos (Miller \& Westra, 1998a). Dessa forma, a dissipação desse grupo de herbicidas é mais rápida em solos com temperaturas e teores de umidade que favoreçam a atividade dos microrganismos (Goetz et al., 1990; Loux \& Reese, 1992). Pode-se supor que, nas condições em que o experimento foi conduzido, a atividade microbiana teve sua ação favorecida, visto que o ambiente de casa de vegetação, sobretudo nos meses de outubro a novembro (segunda etapa do experimento), apresenta diariamente elevadas temperaturas e as parcelas foram irrigadas sempre que se julgou necessário, mantendo-se os teores de umidade adequados à microbiota, sem a ocorrência de estresse hídrico.

Planta Daninha, Viçosa-MG, v. 23, n. 3, p. 535-542, 2005
Comparando as espécies presentes no experimento, nota-se que os valores de $\mathrm{GR}_{50} \mathrm{e}$ $\mathrm{GR}_{80}$ encontrados para $D$. horizontalis foram inferiores aos observados para $B$. plantaginea, ou seja, para obtenção de um dado controle é necessária a aplicação de menos produto sobre o capim-colchão, em relação ao capimmarmelada (Tabela 3). No entanto, embora os dados comprovem que o capim-colchão foi mais sensivel ao herbicida imazapic do que o capim-marmelada, os incrementos de dose exigidos pelas espécies para assegurar um determinado controle são semelhantes. Os resultados de controle deste experimento estão em concordância com aqueles obtidos por Hernandez et al. (2001), em que os autores observaram que o herbicida imazapic - aplicado na dose de $122,5 \mathrm{~g} \mathrm{ha}^{-1}$ sobre solo com $55 \%$ de argila - apresentou controles variando entre muito bom e excelente para as espécies presentes no ensaio, entre elas $D$. horizontalis e B. plantaginea.

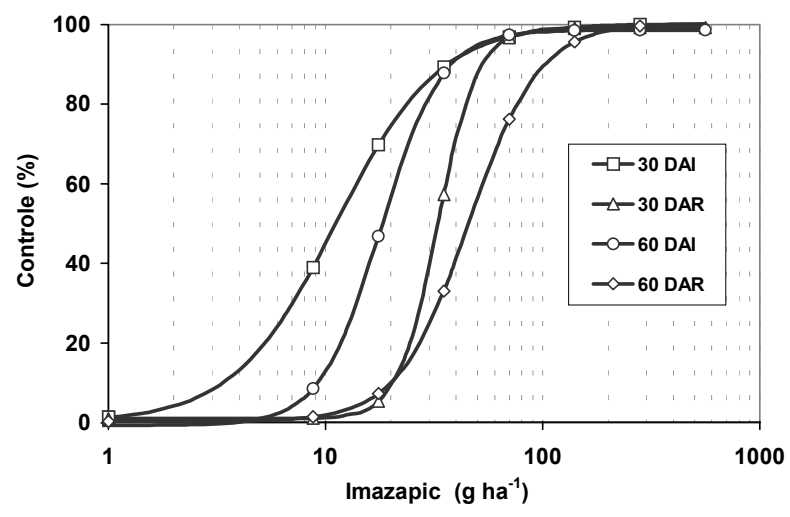

Figura 2 - Controle (\%) de Digitaria horizontalis pelo herbicida imazapic, avaliado aos 30 DAI, 30 DAR, 60 DAI e 60 DAR. Piracicaba, 2004.

A representação gráfica das avaliações de massa seca mostra, em termos percentuais, a eficácia do imazapic sobre as duas plantas daninhas avaliadas no experimento. Em ambas as espécies, o herbicida reduziu em mais de $95 \%$ a massa seca presente nas parcelas expostas à aplicação da dose recomendada do produto e, novamente, a eficácia sobre o capim-colchão foi superior à observada sobre o capim-marmelada (Figura 3). 


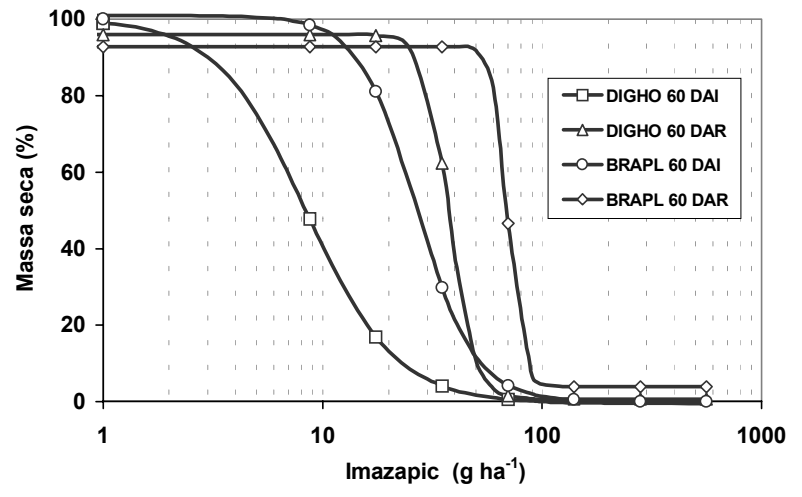

Figura 3 - Massa seca (\%) de Digitaria horizontalis (DIGHO) e Brachiaria plantaginea (BRAPL) reduzida pelo herbicida imazapic, avaliada aos 60 DAI e 60 DAR. Piracicaba, 2004.

Assim, pode-se concluir que: o herbicida imazapic inibiu o desenvolvimento das duas espécies de plantas daninhas, alcançando resultados superiores a $80 \%$ de controle já aos 30 DAI ou 30 DAR, com a dose recomendada; a eficácia no controle de capim-colchão foi ligeiramente superior à verificada no controle do capim-marmelada; e, em razão de seu elevado controle residual, o herbicida imazapic apresentou-se como uma opção interessante para manejo dessas plantas daninhas na cultura da cana-de-açúcar.

\section{LITERATURA CITADA}

ARÉVALO, R. A. Plantas daninhas da cana-de-açúcar. Araras: IAA/PLANALSUCAR - CONESUL, 1979. 46 p.

ASOCIATION LATINOAMERICANA DE MALEZAS ALAM. Recomendaciones sobre unificación de los sistemas de evaluación em ensayos de control de malezas. ALAM, v. 1, p. 35-38, 1974.

BOYD, N. S.; ACKER, R. C. V. The effects of depth and fluctuating soil moisture on the emergence of eight annual and six perennial plant species. Weed Sci., v. 51, p. $725-730,2003$.

CARMONA, R. Problemática e manejo de banco de sementes de invasoras em solos agrícolas. Planta Daninha, v. 10, n. $1 / 2$, p. $5-16,1992$.

CHRISTOFFOLETI, P. J. Curvas de dose-resposta de biótipos resistente e suscetível de Bidens pilosa L. aos herbicidas inibidores da ALS. Sci. Agric., v. 59, n. 3, p. 513-519, 2002.
CHRISTOFFOLETI, P. J.; LÓPEZ-OVEJERO, R. F.

Definições e situação da resistência de plantas daninhas aos herbicidas no Brasil e no Mundo. In: CHRISTOFFOLETI, P.J. (Coord.) Aspectos de resistência de plantas daninhas a herbicidas. 2.ed. Campinas: Associação Brasileira de Ação a Resistência de Plantas aos Herbicidas (HRAC-BR), 2004. p. 3-22.

FREITAS, S. P. et al. Controle químico de Rottboelia exaltata em cana-de-açúcar. Planta Daninha, v. 22, n. 3, p. 461-466, 2004.

GOETZ, A. J.; LAVY, T. L.; GBUR, E. E. Degradation and field persistance of imazethapyr. Weed Sci., v. 38, p. 421-428, 1990.

HERNANDEZ, D. D.; ALVES, P. L. C. A.; MARTINS, J. V. F. Influência do resíduo de colheita de cana-de-açúcar sem queima sobre a eficiência do imazapic e imazapic + pendimethalin. Planta Daninha, v. 19, n. 3, p. 419-426, 2001.

KOGAN, M. A. Malezas; Ecofisiologia y estratégias de control. Santiago: Pontificia Universidad Catolica, 1992. $402 \mathrm{p}$.

KUVA, M. A. et al. Períodos de interferências das plantas daninhas na cultura da cana-de-açúcar. III - capimbraquiária (Brachiaria decumbens) e capim-colonião (Panicum maximum). Planta Daninha, v. 21, n. 1, p. 37-44, 2003.

LORENZI, H. Plantas daninhas e seu controle na cultura da cana-de-açúcar. In: SEMINÁRIO DE TECNOLOGIA AGRONÔMICA, 4., Piracicaba, 1988. Anais... São Paulo: COPERSUCAR, 1988. p. 281-301.

LORENZI, H. Plantas daninhas na cultura da cana-deaçúcar: Plantas daninhas na lavoura do nordeste brasileiro. In: ENCONTRO TÉCNICO GOAL, CANA-DE-AÇÚCAR, 4., 1995, Recife. Anais... Recife: 1995.

LOUX, M. M.; REESE, K. D. Effect of soil pH on absorption and persistance of imazaquin. Weed Sci., v. 40, p. 490-496, 1992.

MANGELS, G. Behavior of the imidazolinone herbicides in soil - A review of the literature. In: SHANER, D. L.; O'CONNOR, S. L. (Eds.). The Imidazolinone Herbicides. Boca Raton: CRC, 1991. p. 191-209.

MILLER, P.; WESTRA, P. Herbicide selectivity and performance. Crop Series - Production. Fort Collins: 1998a. (Colorado State University Cooperative Extension, 563)

Planta Daninha, Viçosa-MG, v. 23, n. 3, p. 535-542, 2005 
MILLER, P.; WESTRA, P. Herbicide behavior in soils. Crop Series - Production. Fort Collins: 1998b. (Colorado State University Cooperative Extension, 562)

PITELLI, R. A. Interferência das plantas daninhas em culturas agrícolas. Inf. Agropec., v. 11, n. 129, p. 16-27, 1985.

PITELli, R. A.; PITELLI, R. L. C. M. Biologia e ecofisiologia das plantas daninhas. In.: VARGAS, L.; ROMAN, E. S. (Eds.) Manual de manejo e controle de plantas daninhas. Bento Gançalves: Embrapa Uva e Vinho, 2004. p. 29-56.
PROCÓPIO, S. O.; SILVA, A. A.; VARGAS, L. Manejo e controle de plantas daninhas em cana-de-açúcar. In.:

VARGAS, L.; ROMAN, E. S. (Eds.). Manual de manejo e controle de plantas daninhas. Bento Gançalves:

Embrapa Uva e Vinho, 2004. p. 397-452.

ROLIM, J. C.; CHRISTOFFOLETI, P. J. Período crítico de competição das plantas daninhas com cana planta de ano. Saccharum APC, v. 5, n. 22, p. 21-26, 1982.

SEEFELDT, S. S.; JENSEN, S. E.; FUERST, E. P. Loglogistic analysis of herbicide dose-response relationship. Weed Technol., v. 9, p. 218-227, 1995. 